\title{
Penerapan Web Mobile Pada Sistem Informasi Pencarian Dan Pemesanan Rumah Kos
}

\author{
Dwi Oktarina $^{1}$, Darmanta Sukrianto ${ }^{2}$, Wistiana $^{3}$ \\ Program Studi Sistem Informasi, STIKOM Pelita Indonesia Pekanbaru ${ }^{1}$ \\ Program Studi Manajemen Informatika, AMIK Mahaputra Riau ${ }^{2,3}$ \\ dwi.oktarina@lecturer.pelitaindonesia,ac.id ${ }^{1}$,darman1407@gmail.com², wistiana.tia@gmail.com³
}

\begin{tabular}{l}
\hline Article Info \\
\hline History: \\
Dikirim 21 Oktober 2018 \\
Direvisi 30 November 2018 \\
Diterima 17 Januari 2019
\end{tabular}

Kata Kunci:

Pemesanan

Pencarian

Sistem Informasi

Web Mobile

\begin{abstract}
Abstrak
Tempat tinggal atau rumah kos merupakan kebutuhan para pendatang yang akan melanjutkan pedidikan atau mencari nafkah ke suatu daerah. Permasalahan dalam mencari informasi rumah kos ada beragam, tidak mengetahui daerah dan sulit mendapatkan rumah kos yang sesuai dengan keinginan. Oleh karena itu, menimbulkan permasalahan bagaimana pencari kos dapat menemukan rumah kos, mendapatkan informasi rumah kos, dan memesan rumah kos yang mereka inginkan dengan mudah. Pembuatan Aplikasi sistem informasi pencarian dan pemesanan kos berbasis web mobile dengan bahasa pemrograman PHP dan database MySQL, diharapkan dapat sangat mendukung dan memudahkan pencarian, pemesanan, dan promosi rumah kos di kota pekanbaru. Hasilnya adalah Sistem Informasi Pencarian dan Pemesanan Kos Berbasis Web Mobile yang dapat memberikan informasi dan deskripsi dari rumah kos kepada pencari kos, dapat mesanan kos menggunakan perangkat portable seperti smartphone dan gadget/tablet melalui jaringan internet serta menjadi media promosi bagi pemilik kos.
\end{abstract}

(C) This work is licensed under a Creative Commons AttributionShareAlike 4.0 International License.

\footnotetext{
Koresponden:

Dwi Oktarina,

Sekolah Tinggi Ilmu Komputer (STIKOM) Pelita Indonesia Pekanbaru

Email : dwi.oktarina@lecturer.pelitaindonesia.ac.id
}

\section{PENDAHULUAN}

Internet bukan merupakan hal yang asing lagi bagi masyarakat khususnya bagi dunia usaha. Internet sekarang ini banyak dimanfaatkan sebagai media promosi oleh berbagai instansi, baik itu perusahaan maupun lembaga pemerintah. Di Indonesia sendiri tercatat lebih dari 25 juta orang menggunakan internet, jumlah ini terus meningkat secara drastic setiap harinya [1].

Meskipun di kota pekanbaru sudah banyak rumah kos yang berdiri, masih ada kendala bagi pencari kos dalam mencari kos yang sesuai dengan keinginan. Biasanya terkendala seperti tidak mengetahui wilayah, sehingga harus mencari dan menelusuri wilayah untuk mendapatkan kos yang sesuai keinginan mereka baik dari segi lokasi yang berdekatan dengan tujuan mereka, fasilitas, dan tarif. Hal ini tentunya akan menyulitkan pencari kos untuk mendapatkan informasi dan menyita banyak waktu untuk mengunjungi satu persatu rumah kos demi mendapatkan tempat kos yang sesuai. Cara promosi pemilik yang masih umum, yang hanya menggunakan pamflet, tulisan terima kos, dan area promosi hanya sebatas dimana pamflet tersebut ditempel tentunya cakupan informasi tersebut tidak terlalu luas. Untuk melakukan pemesanan kos, biasanya pencari kos melakukan pemesanan secara langsung ataupun melalui telepon dengan pemilik. 
Penelitian ini merujuk dari beberapa penelitian sebelumnya mengenai sistem informasi rumah kos antara lain oleh Reynold G, dkk tahun 2016 yang berjudul "Boarding House Locator And Student Monitoring System In Naval, Biliran Province, Pilipines" [2]. Sandi Kosasi tahun 2014 dengan judul "Sistem Informasi Geografis Pemetaan Tempat Kos Berbasis Web" [3]. Dadi Rosadi, Feby Oktarista Andriawan tahun 2016 dengan judul "Aplikasi Sistem Informasi Pencarian Tempat Kos Di Kota Bandung Berbasis Android" [4].

Aplikasi sistem informasi pencarian dan pemesanan kos berbasis web mobile, merupakan salah satu solusi yang dapat menyelesaikan permasalahan yang telah diuraikan diatas. Dengan menggunakan perangkat portable seperti smartphone dan gadget/tablet yang terhubung dengan jaringan internet pencarian dan pemesanan kos tersebut dapat menyediakan informasi lokasi rumah kos, tarif, fasilitas, pemesanan rumah kos, serta membantu pemilik dalam mempromosikan rumah kos mereka.

\section{METODE PENELITIAN}

\subsection{Pengumpulan Data}

Untuk pengumpulan data dan identifikasi masalah pada penelitian ini menggunakan metode sebagai berikut:

1. Observasi

Observasi dapat dilakukan sesaat atau dapat diulang, dalam penelitian ini yang menjadi objek penelitian adalah bagaimana cara pendatang mendapatkan informasi dan menemukan rumah kos di Kota Pekanbaru dan bagaimana pemilik kos memasarkan rumah kosnya.

2. Wawancara

Proses tanya jawab lisan atau tulisan dimana dua orang atau lebih berhadapan secara fisik dan wawancara ini di lakukan antara peneliti dengan mahasiswa atau pegawai dan pemilik kos.

\subsection{Konsep Teori}

\subsubsection{Sistem Informasi}

Sistem Informasi adalah sustu jaringan kerja dari prosedur-prosedur yang saling berkaitan, berkumpul untuk melakukan suatu kegiatan atau untuk menyelesaikan suatu sasaran tertentu [5]. Dalam arti luas sistem informasi dapat dipahami sebagi kumpulan subsistem yang saling berhubungan, berkumpul bersama-sama dan membentuk satu kesatuan, saling berinteraksi dan bekerja sama antara bagian satu dengan yang lainnya dengan cara-cara tertentu untuk melakukan fungsi pengolahan data, menerima masukan (input) berupa data-data, kemudian mengolahnya (prccessing), dan menghasilkan keluaran (output) berupa informasi sebagai dasar bagi pengambilan keputusan yang berguna dan mempunyai nilai nyata yang dapat dirasakan akibatnya baik pada saat itu juga maupun dimasa mendatang, mendukung kegiatan operasional, manajerial, dan strategis organisasi, dengan memanfaatkan berbagai sumber daya yang ada dan tersedia bagi fungsi tersebut guna mencapai tujuan [6].

\subsubsection{Aplikasi Web Mobile}

Aplikasi mobile dapat diartikan sebagai sebuah produk dari sistem komputasi mobile, yaitu sistem komputasi yang dapat dengan mudah dipindahkan secara fisik dan yang komputasi kemampuan dapat digunakan saat mereka sedang dipindahkan. Aplikasi Web Mobile (Mobile Web Application) merupakan aplikasi mobile yang tidak perlu diinstal atau dikompilasi pada perangkat target. Menggunakan XHTML, CSS, dan JavaScript, aplikasi ini mampu memberikan penggunka pengalaman layaknya aplikasi native/asli [7]. 


\subsubsection{UML}

Unified Modelling Language (UML) adalah sebuah bahasa untuk menetukan, visualisasi, kontruksi, dan mendokumentasikan artifact (bagian dari informasi yang digunakan atau dihasilkan dalam suatu proses pembuatan perangkat lunak. Artifact dapat berupa model, deskripsi atau perangkat lunak) dari sistem perangkat lunak, seperti pada pemodelan bisnis dan system non perangkat lunak lainnya. UML merupakan suatu kumpulan teknik terbaik yang telah terbukti sukses dalam memodelkan system yang besar dan kompleks. UML tidak hanya digunakan dalam proses pemodelan perangkat lunak, namun hampir dalam semua bidang yang membutuhkan pemodelan [8].

Berikut ini adalah beberapa konsep dasar dalam pemodelan Unified Modelling Language (UML) :

1. Use Case Diagram merupakan pemodelan untuk melakukan (behaviour) system informasi yang akan dibuat.

2. Actifity Diagram menggambarkan Workflow (aliran kerja) atau aktifitas dari sebuah sistem atau proses bisnis.

3. Sequence Diagram menggambarkan kelakuan objek pada use case dengan mendiskripsikan waktu hidup objek dan message yang dikirimkan dan diterima antar objek.

4. Component Diagram dibuat untuk menujukan organisasi dan ketergantungan diantara kumpulan komponen dalam sebuah sistem.

5. Deployment Diagram menunjukan konfigurasi komponen dalam proses eksekusi aplikasi [9].

\subsubsection{Metode Pengembangan Sistem}

Model Waterfall menyediakan pendekatan alur hidup perangkat lunak secara terurut. Tahapan-tahapan pada proses pengembangan system menggunakan waterfall ini adalah sebagai berikut :

1. Analisis kebutuhan perangkat lunak

Pada tahap ini kegiatan yang dialkukan ialah pengumpulan kebutuhan yang dilakukan secara intensif untuk menspesifikasikan kebutuhan dari perangkat lunak agar dapat dipahami perangkat lunak yang bagaimana yang dibutuhkan user.

2. Desain

Desain perangkat lunak adalah proses multilangkah yang focus pada desain pembuatan program perangkat lunak termasuk struktur data arsitektur perangkat lunak, representasi antarmuka, dan prosedur pengkodean.

3. Pembuatan kode program

Desain harus ditranslasikan ke dalam program perangkat lunak. Hasil dari tahap ini adlah program computer sesuai denagn desain yang telah dibuat pada tahap desain.

4. Pengujiaan

Pengujian focus pada perangkat lunak secara dari segi logic dan fungsional dan memastikan bahwa semua bagian sudah diuji. Hal ini dilakukan untuk meminimalisasi kesalahan (error) dan memastikan keluaran yang dihasilakn sesuai dengan yang diinginkan.

5. Pendukung (support) atau pemeliharaan (maintenance)

Tahap pendukung atau pemeliharaan dapat mengulangi proses pengembangan mulai dari analisis spesifikasi untuk perubahan perangakat lunak yang sudah ada, tapi tidak untuk membuat perangkat lunak baru [10].

\subsection{Perancangan Sistem}

\subsubsection{Use Case}




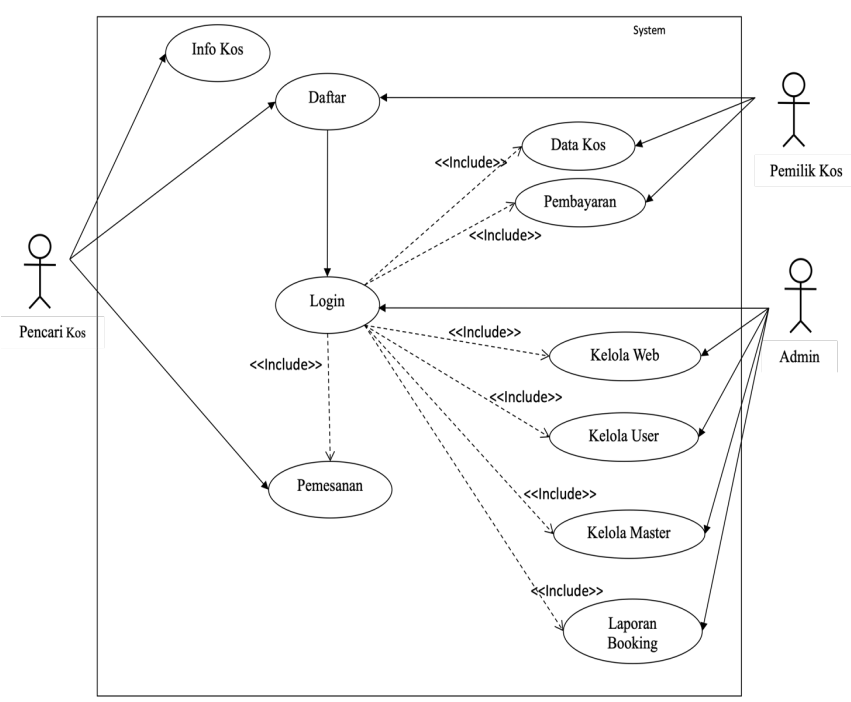

Gambar 1. Use Case Diagram

\subsubsection{Activity Diagram}

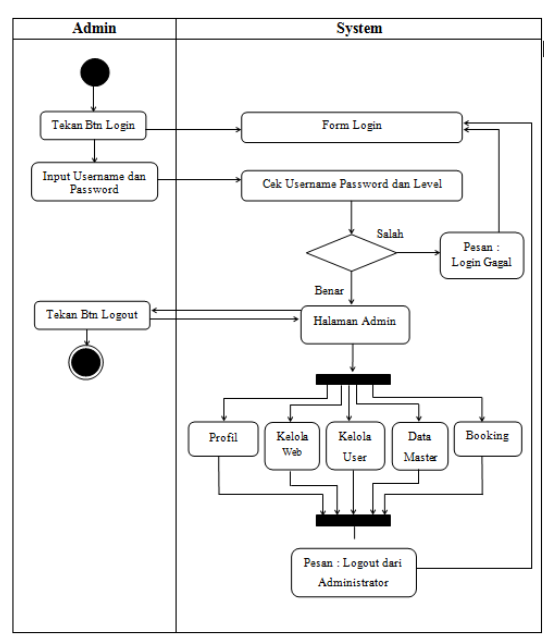

Gambar 2. Activity Diagram Admin

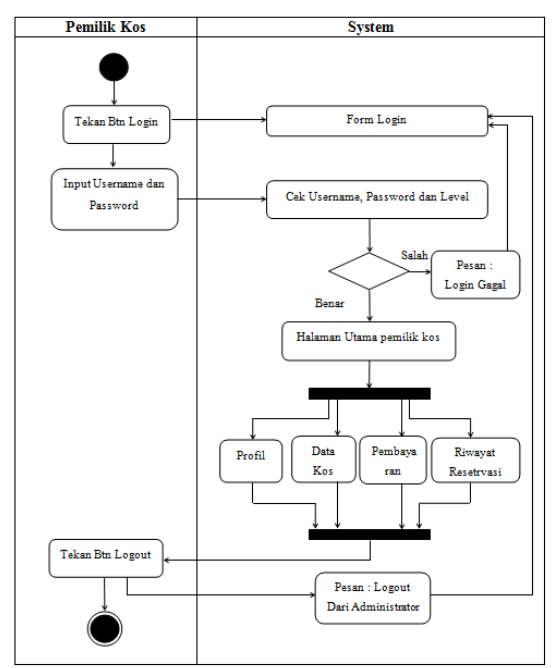

Gambar 3. Activity Diagram Pemilik Kos 


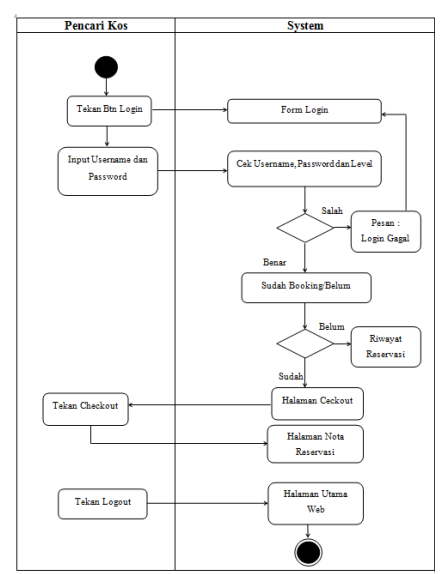

Gambar 4. Activity Diagram Pencari Kos

\subsubsection{Class Diagram}

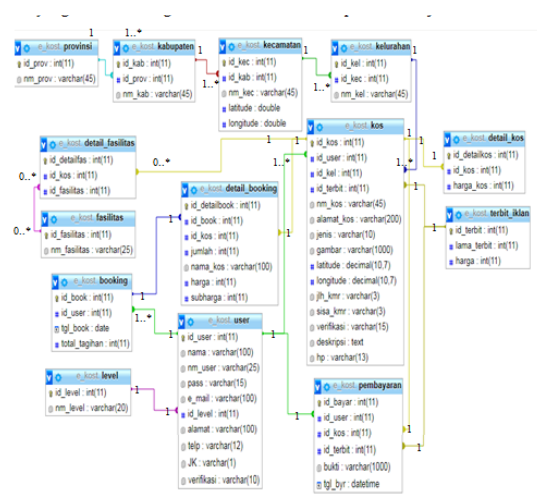

Gambar 5. Class Diagram

\subsubsection{Sequence Diagram}

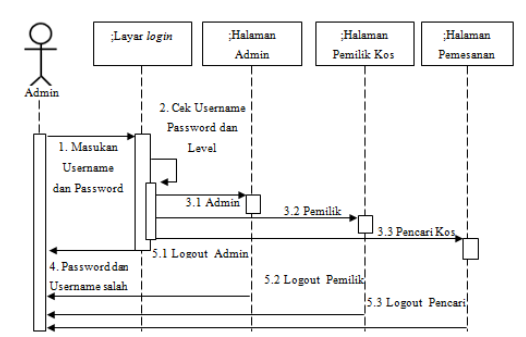

Gambar 6. Squence Diagram Admin

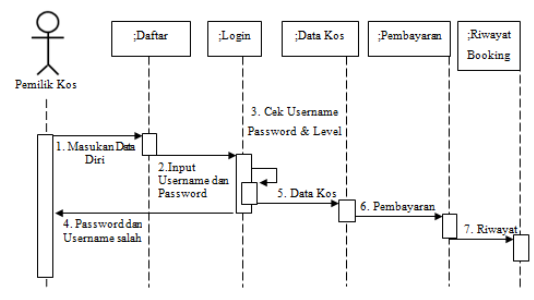

Gambar 7. Squence Diagram Pemilik Kos 


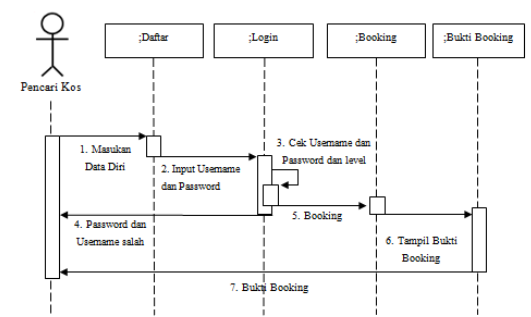

Gambar 8. Squence Diagram Pencari Kos

\section{HASIL DAN PEMBAHASAN}

\subsection{Halaman Utama}

Pada halaman utaman ini para pencari kos dapat melihat model dan tipe kos yg mereka inginkan atau bisa juga dengan cara mencari langsung pada kolom pencarian dengan menggunakan nama kos atau alamat kos.

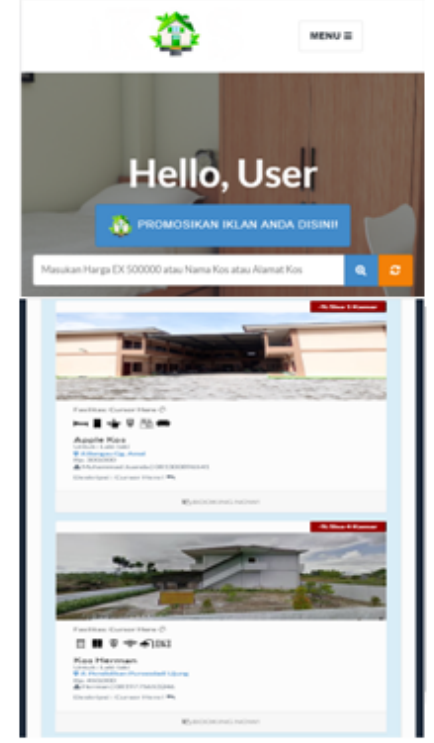

Gambar 9. Halaman Utama

\subsection{Halaman Maps}

Pada halaman maps ini memberikan informasi titik lokasi kos-kosan yang terdaftar pada aplikasi yang berada di Kota Pekanbaru, pengguna web dapat mengklik pada pin berwarna merah untuk mengetahui nama kos yang berada pada titik tersebut.

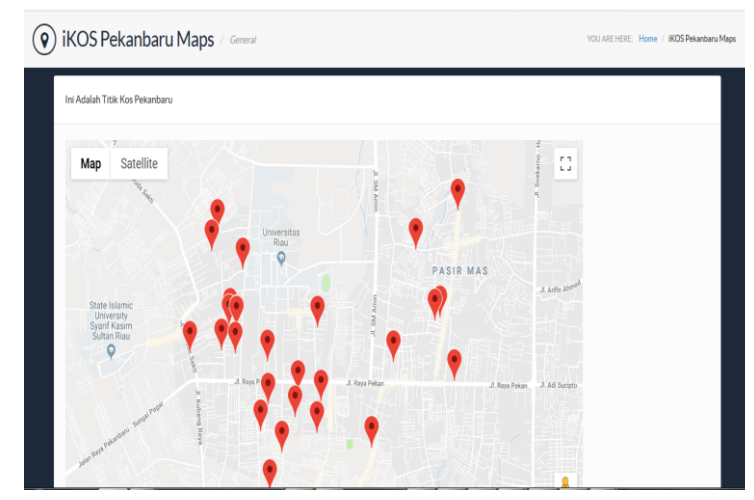

Gambar 10. Halaman Maps 


\subsection{Halaman Register}

Halaman registrasi ini merupakan halaman untuk user mendaftarkan dirinya agar mendapatkan hak akses sebagai pengguna aplikasi. Saat melakukan pendaftaran pabila user tidak mengisi salah satu kolom yang tidak boleh kosong saat menekan tombol register me maka akan ada pemberitahuan agar untuk mengisi kolom yang kosong.

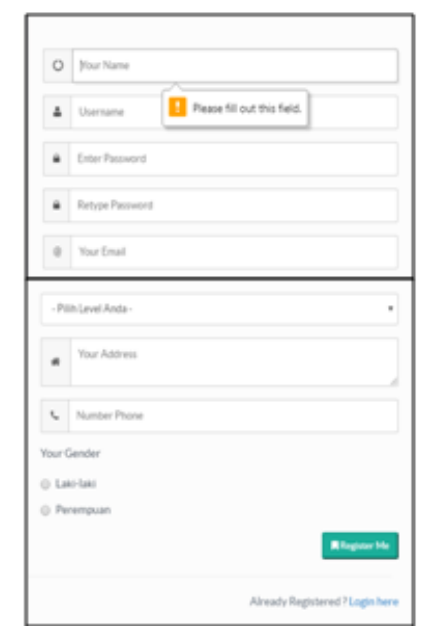

Gambar 11. Halaman Register

\subsection{Halaman Login}

Halaman ini merupakan halaman bagi user untuk dapat menggunakan aplikasi pencarian dan pemesanan kos online, sesuai dengan level aksesnya masing-masing, user harus memasukan username dan password sesuai dengan apa yang didaftarkan pada halaman register.

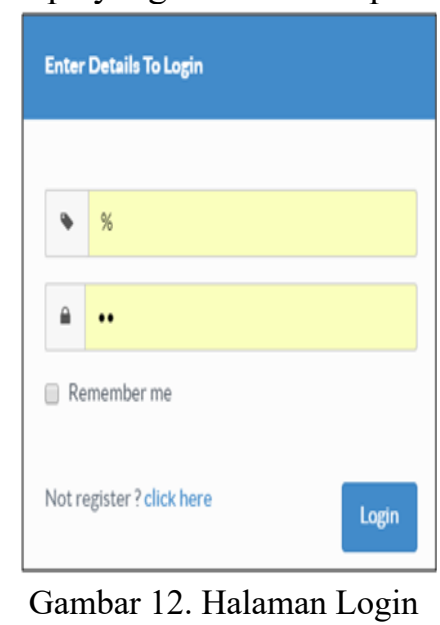

\subsection{Halaman Detail Data Kos}

Pada halaman ini pencari kos bisa melihat detail kos mulai dari harga, fasilitas dan ketersedian kamar. 


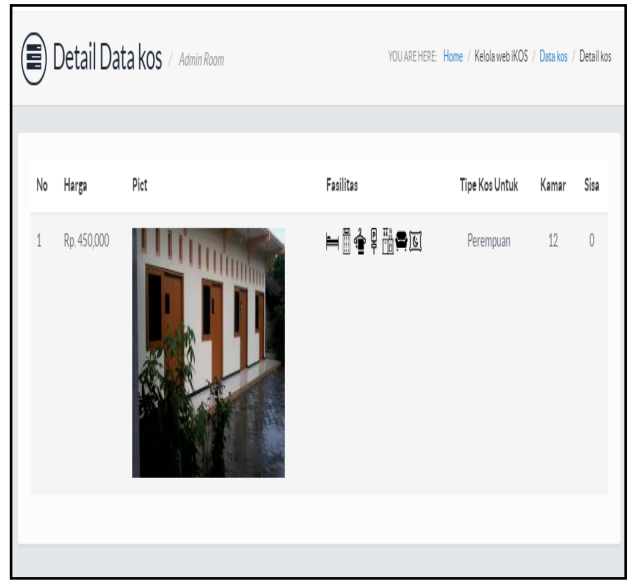

Gambar 13. Halaman Detail Data Kos

\subsection{Halaman Pemesanan Sementara}

Saat pencari kos menekan tombol booking pada kos yang ingin di booking maka halaman akan di arahkan ke tampilan booking sementara, pada halaman ini pencari kos masih bisa membatalkan pesanannya, jika ingin memesan kos maka pencari kos harus menekan tombol checkout to your chart.

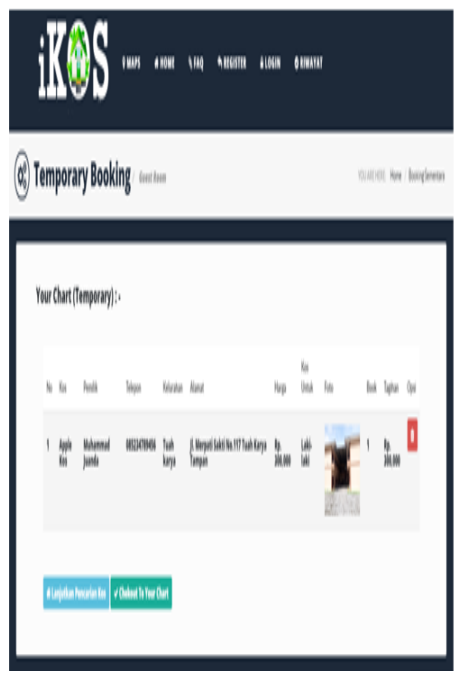

Gambar 14. Halaman Pemesanan Sementara

\subsection{Halaman Booking Checkout}

Halaman ini pencari kos sudah memilih rumah kos yang sesuai dengan keinginan. 


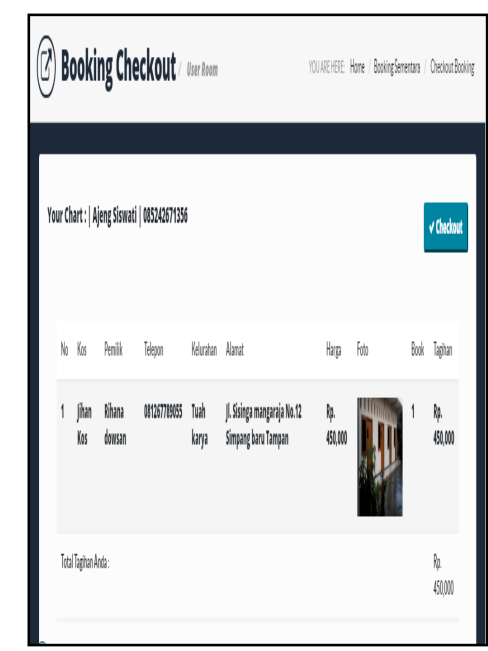

Gambar 15. Halaman Booking Checkout

\subsection{Halaman Verifikasi Pembayaran}

Halaman ini untuk mengupload bukti pembayaran yang telah dilakukan oleh si pencari kos.

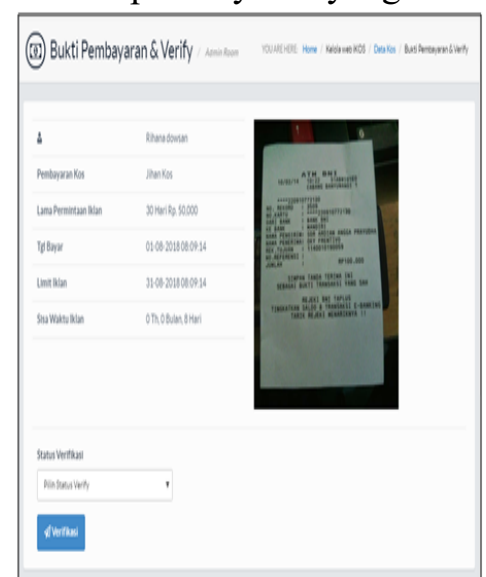

Gambar 16. Halaman Verifikasi Pembayaran

\subsection{Halaman Nota Reservasi}

Nota ini berfungsi untuk mengetahui bahwa si pencari kos telah membayar kos yang dia inginkan. 


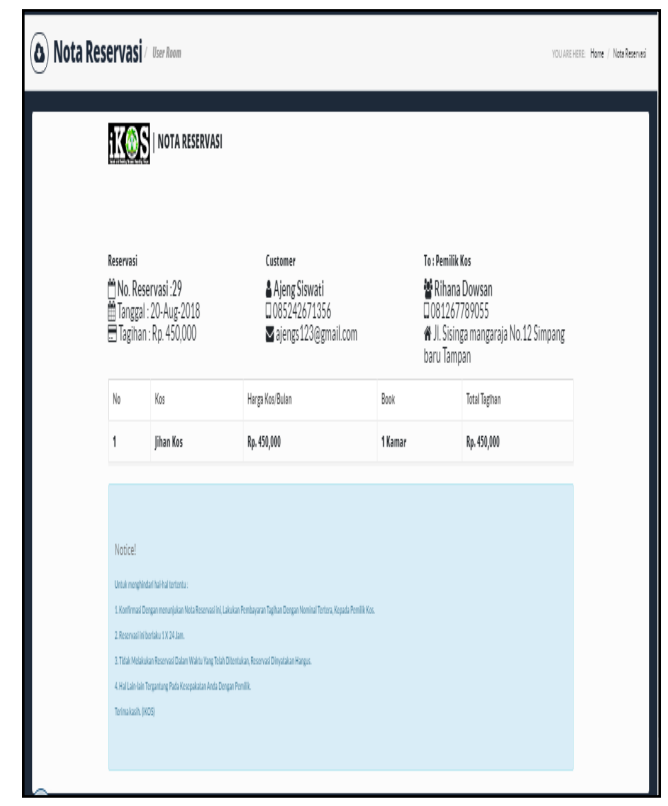

Gambar 17. Nota Reservasi

\section{KESIMPULAN}

Berdasarkan hasil pengujian dapat diambil beberapa kesimpulan sebagai berikut :

1. Dengan adanya sistem informasi pencarian dan pemesanan rumah kos di Kota Pekanbaru berbasis web mobile, telah tersedia sarana untuk memasarkan, mencari, serta memesan rumah kos secara online.

2. Dapat memberikan informasi dan gambaran bagi pencari kos seperti fasilitas, ketersediaan kamar, informasi biaya sewa, dan lokasi rumah kos yang ada di Kota Pekanbaru.

3. Data-data rumah kos dapat dikelola secara online oleh pemilik-pemilik kos, sehingga data yang diberikan realtime dan akan lebih mudah dalam melakukan promosi terhadap rumah kos yang dikelolanya.

\section{DAFTAR PUSTAKA}

[1] D. Irawan, "Sistem Informasi Reservasi Hotel 929 Berbasis Web Mobile Di Kota Lubuklinggau," J. Informanika, vol. 3, no. 2, pp. 93-102, 2017.

[2] R. G. Bustillo and B. G. Batistis, "BOARDING HOUSE LOCATOR AND STUDENT MONITORING SYSTEM IN NAVAL ," IJESRT, vol. 5, no. 8, pp. 468-480, 2016.

[3] S. Kosasi, "Sistem informasi geografis pemetaan tempat kost berbasis web," CSRID J., vol. 6, no. 3, pp. 171-181, 2014.

[4] D. Rosadi and F. O. Andriawan, "Aplikasi sistem informasi pencarian tempat kos di kota bandung berbasis android," J. Comput. Bisnis, vol. 10, no. 1, pp. 50-58, 2016.

[5] B. Usmanto, R. Immawan, K. P. Sari, and M. I. Mahdi, "Implementasi Web Mobile Sebagai Media Informasi Pemberdayaan Masyarakat Di Desa Pirngadi,” JUTEKS, vol. 1, no. 1, pp. 32-40, 2018.

[6] A. EFENDI and H. PRAYOGO, "Sistem Informasi Geografis Satuan Kerja Perangkat Daerah Kota Pekanbaru," ITJRD, vol. 1, no. 1, pp. 9-15, 2017.

[7] M. Abdurahman, "Sistem Informasi Jadwal Perkuliahan Berbasis Web Mobile Pada Politeknik Sains Dan Teknologi Wiratama Maluku Utara," Journal, Indones. Netw. Secur., vol. 5, no. 2, pp. 49-56, 2016.

[8] H. GUNAWAN, SUCI PRIHATI, and I. P. Siwi, "Sistem Informasi Geografis Lokasi Wisata Kuliner Di Kota Pekanbaru Berbasis Web," ITJRD, vol. 1, no. 1, pp. 60-70, 2017.

[9] S. S. Sundari and I. Komarudin, "PERANCANGAN SISTEM INFORMASI RUMAH 
KOST BERBASIS WEB DAN SHORT MESSAGE SERVICE ( SMS ) MENGGUNAKAN," in Seminar Nasional Informatika 2015, 2015, pp. 333-337.

[10] A. Rasid, Supriyono; and R. Setawan, "Aplikasi Reservasi Menu Restoran Berbasis Web dan Mobile Android di Cowek Ireng," SITECH, vol. 1, no. 1, pp. 21-30, 2018. 